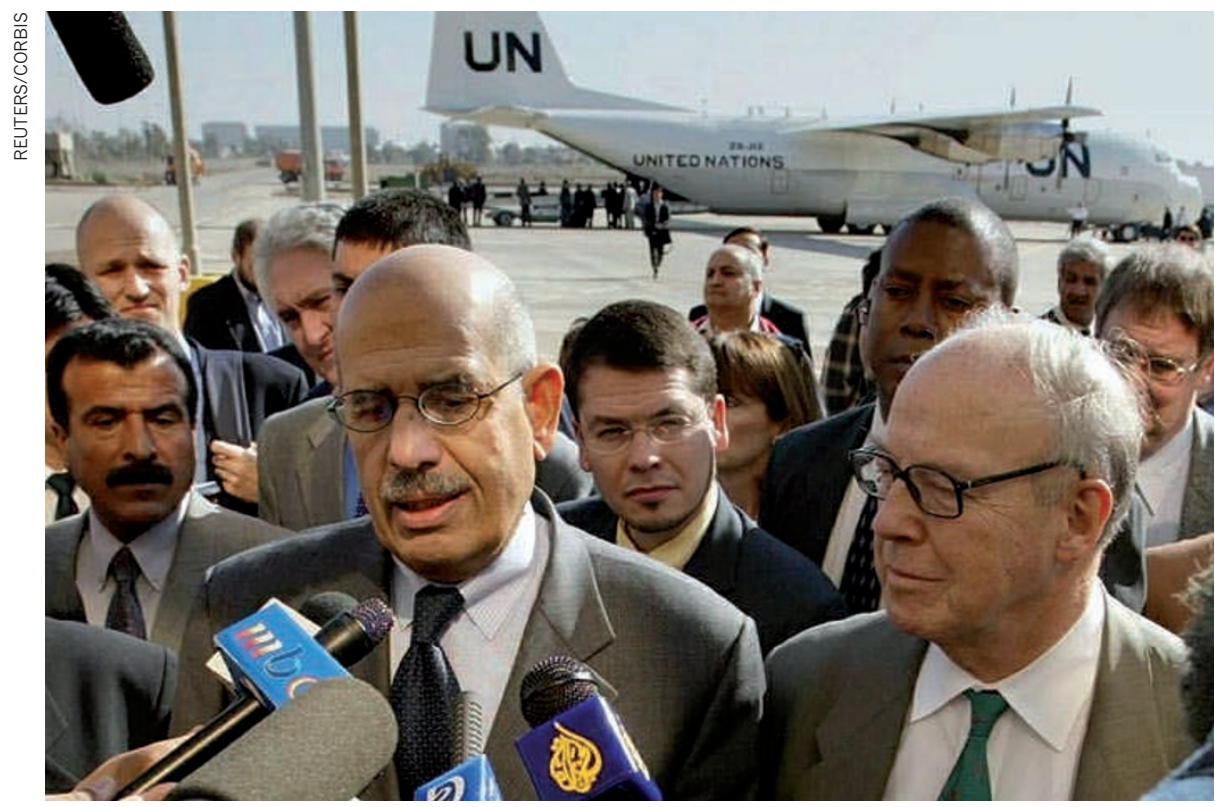

UN inspectors Mohamed ElBaradei (left) and Hans Blix (right) found no nukes in Iraq in 2002.

POLICY

\title{
Towards nuclear zero
}

\section{Fact-packed final volume of a quartet on nuclear security is required reading, writes Joseph Cirincione.}

\section{$\mathrm{T}$} he first chapter of The Twilight of the Bombs justifies its purchase. Historian Richard Rhodes refutes the myth that the Israeli bombing of an Iraqi nuclear reactor at Osirak in 1981 set back Saddam Hussein's nuclear-weapons programme - a raid that some now cite as a model for future attacks on Iran. Rhodes shows that the bombing accelerated the programme and drove it underground. By 1991, Iraq was close to possessing a nuclear bomb.

Rhodes sets the record straight in this volume, the fourth book in his atomic quartet. The first, The Making of the Atomic Bomb (Simon \& Schuster, 1987), won a Pulitzer Prize in 1988. In 1996, Dark Sun (Simon \& Schuster) detailed the history of the hydrogen bomb and the US-Soviet nuclear-arms race, and Arsenals of Folly (Knopf, 2007) documented the final decades of the cold war. His latest, an authoritative review of the rise and partial resolution of nuclear dangers since the end of the cold war, is required reading for any debate about nuclear security policy.

Its central, if unarticulated, theme is that policy matters. By examining history, we can determine which policies worked to reduce nuclear threats and which made matters worse. Rhodes convincingly counters the fatalistic views that dominate on the far right: that proliferation is inevitable, treaties cannot stop the spread of the bomb,

and military force is the only way to prevent hostile regimes from getting nuclear weapons. He does so by recounting the facts.

Rhodes takes us through the 1991 Gulf War and inside the United Nations inspections that uncovered and dismantled Saddam's weapons programmes. He allows the inspectors - Robert Gallucci, David Kay, Rolf Ekéus, Hans Blix and others - to tell their own stories. These reminiscences become high drama as inspectors race to outwit and outrun Saddam's henchmen. Despite tensions among them, the teams persist until their game-changing discovery in September 1991 of hidden designs

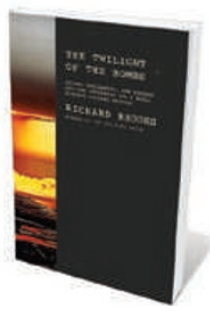

The Twilight of the Bombs: Recent Challenges, New Dangers, and the Prospects for a World without Nuclear Weapons RICHARD RHODES Random House: 2010 352 pp. $\$ 27.95$ confirming the previously secret bomb programme. Gallucci calls it "one of the best moments of my nonproliferation life".

The book also details the patient work of US Senators Sam Nunn and Richard Lugar, defence secretary Les Aspin, secretary of state James Baker, ambassador Thomas Graham and others in the early 1990s as they carefully disarmed the nuclear 'hurt locker' the Soviet Union left behind. Years of joint work by Democrats and Republicans eliminated the nuclear weapons inherited by Belarus, Ukraine and Kazakhstan and provided security for the ones that threatened to get loose as empires collapsed - all against a high whine of conservative denunciation of the programmes as aiding former communists. Rhodes explains the mysterious 'flash in the South Atlantic' in September 1979 - a suspected South African or Israeli nuclear test and dissects South Africa's decision in 1990 to dismantle its seven secret nuclear devices.

Rhodes does a brilliant job of tracking the fabricated fears generated by US officials to justify a second war with Iraq. Former vicepresident Dick Cheney's August 2002 speech began the cascade of falsehoods. We "now know that Saddam has resumed his efforts to acquire nuclear weapons", Cheney said, on the basis of sources and first-hand testimony from defectors “including Saddam's own son-in-law". But Rhodes documents that there was no evidence of an effort to restart any of the past weapons programmes.

It is necessary to go over this old ground because many people still do not have the history correct. Earlier this month, for example, Wall Street Journal columnist Daniel Henninger harshly criticized President Barack Obama's efforts to "turn the page on Iraq" with a long justification of the war, writing that the invasion "took one of these nuclearobsessed madmen off the table". This assumes that Saddam had, or wanted, a nuclear-bomb programme at the time of the 2003 invasion, and that war was the only response.

Rhodes tells a different tale. First, he shows that US intelligence officials knew by the autumn of 2002 that two central claims of the George W. Bush administration were wrong: Saddam did not try to buy yellow cake (uranium ore) from Niger, and aluminium tubes intercepted by US and Jordanian officials were not for uranium-enrichment centrifuges as claimed, but for artillery rocket casings. These experts were rebuffed in favour of the politicized findings developed by officials in the Department of Defense. The intelligence "was fixed around the policy", as Richard Dearlove, director of the British intelligence agency MI6, wrote to his government in July 2002, seven months before the war began.

More importantly, as Rhodes recounts, the UN intelligence efforts got it right. Inspectors allowed back into Iraq searched everywhere the US officials told them they would find weapons. They found nothing. They begged for more time to complete their surveys. They were denied. The war cost thousands of US and coalition combat deaths, hundreds of thousands of Iraqi deaths and at least US $\$ 1$ trillion borrowed to pay for it. Blix tells Rhodes that his inspections would have cost $\$ 80$ million — "and would have worked as well". 
Rhodes has some good news. Since the end of the cold war, he says, "the irregular but unmistakable trend in international relations has been towards the reduction and elimination of nuclear arsenals". It is a trend obscured by the real dangers of new programmes in Iran and North Korea and by the threat-inflation arguments used by zealots against armscontrol treaties, but it is borne out by the historic arc traced by Rhodes.

Global nuclear arsenals are one-third of the size they were at the height of the cold war, shrinking from an estimated 70,000 nuclear warheads in 1986 to 22,000 today, with $96 \%$ of these held by the United States and Russia. More countries have given up nuclear weapons and programmes in the past 25 years than have tried to acquire them, including Argentina and Brazil in the 1980s; Ukraine, Belarus, Kazakhstan and South Africa in the 1990s; and Libya and Iraq in the 2000s. Experts agree that the gravest threat now is from nuclear terrorism. Following from that assessment is a growing consensus that, as Rhodes says, "the world faces a stark choice: eliminate nuclear weapons and secure their fissile explosives or expect them to be used." But how to eliminate them?

Rhodes is no pacifist. "A war [as with Iraq] might well be a last resort against a resistant proliferator," he concedes. But his preferred methods are the "nuts-andbolts" policies worked out over the past 15 years by international commissions and realists such as US politicians George Shultz, Sam Nunn, Bill Perry and Henry Kissinger - and increasingly adopted by the United States, the European Union and countries elsewhere.

The emerging nuclear security consensus includes a commitment to eliminate nuclear weapons over time and practical steps toward that goal, including verifiable reductions in US and Russian arsenals, a ban on nuclear tests and an end to the production of weapons materials. In a world moving towards nuclear zero, nations are more likely to cooperate to lock up all supplies of highly enriched uranium and plutonium - thus denying terrorists the one part of the bomb they cannot make themselves - and to isolate and punish states that try to start new programmes.

Rhodes's unflinching examination over the past 25 years of the promise and horrors of nuclear weapons has educated a generation. I hope his vision for the next 25 inspires another.

Joseph Cirincione is president of Ploughshares Fund, USA, and author of Bomb Scare: The History and Future of Nuclear Weapons.

e-mail:joe@ploughshares.org

\section{ENVIRONMENT}

\section{Venice's fragile lagoon}

\author{
A section of salt marsh in a Biennale pavilion links the \\ city and its environment, notes Colin Martin.
}

$\mathrm{D}$ azed by Venice's architecture, few people look beyond the city to its lagoon. To raise awareness of the lake's ecological complexity and beauty, environmental scientist Jane da Mosto has, with permission, removed a 15-metre-square section of Venetian salt marsh and installed it in a stainless-steel tank washed by artificial tides. It is on display in the British Pavilion of the 12th International Architecture Exhibition (the Venice Biennale) until 21 November.

"Venice is so fragile, in its physical, environmental and even socio-economic dimensions, that we must develop viable plans to ensure its survival," says da Mosto. First-hand experience of nature often generates more emotion than dry scientific data: she reports that locals and visitors who had thought of the lagoon as just a muddy space have been moved by the marsh's beauty.

The Venice lagoon is a winter migration halt and breeding area for 200,000 birds. Along with Tunisia's Gulf of Gabès, it is one of the most important wetlands in the Mediterranean Basin. The exhibition includes taxidermic specimens of 24 of the 60 species of water bird found in the lagoon, lent by the Venetian Museum of Natural History. Maps and panels, prepared by da Mosta and Tom Spencer, director of the Coastal Research Unit at the University of Cambridge, UK, detail the lagoon's wildlife and flora, rivers, inlets, marshlands, water levels and ecology.

In addition to seasonal flooding and mass tourism, the urban fabric of Venice is challenged by rising water levels. Da Mosto and Spencer are analysing historical and contemporary data on the area's geography, hydrology, flora and fauna to illuminate the fragile ecological balance of the lagoon and the consequences of its disruption for Venice's buildings. They aim to articulate how the fate of the city and its waters are connected.

Until the collapse of the Venetian Republic in 1797, the lagoon

Villa Frankenstein: Venice Lagoon The British Pavilion, 12th International Architecture Exhibition, Venice, Italy Until 21 November 2010

was well maintained. Waterways were managed, and the waters provided a livelihood for fishermen in the city and outlying islands. When rail and land were established, Venetians' connections to the lagoon dwindled as they came to depend more on tourism for their income.

Appropriately, the exhibition catalogue is printed on 'Alga Carta', a specialist Venetian paper made from harvested algae that would otherwise clog the lagoon. It will be decades before scientists can write 'done' against their lagoon investigation, as the nineteenth-century art critic John Ruskin did for his exploration of the city's architecture. But this is an excellent start.

Colin Martin is a writer based in London. e-mail:cmpubrel@aol.com road links to the main-

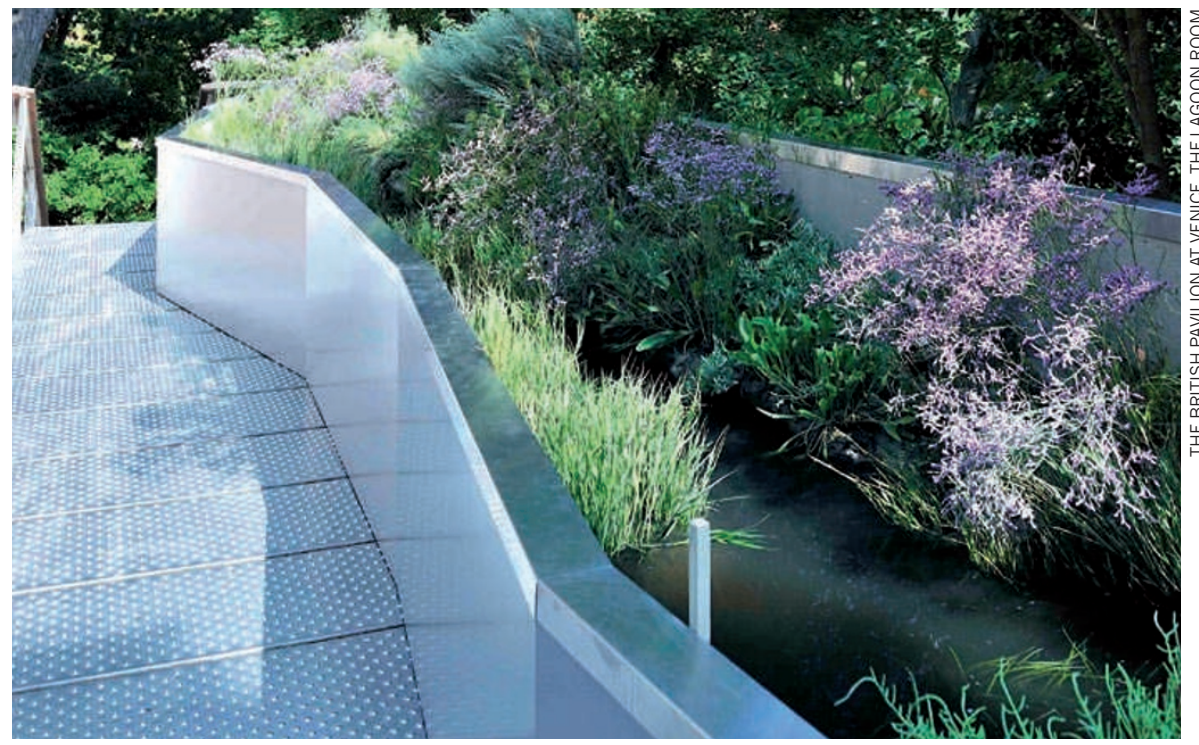

The transplanted salt marsh highlights the importance of the 'muddy space' outside Venice. 